ENTREPRENEURSHIP AND SUSTAINABILITY ISSUES

ISSN 2345-0282 (online) http://jssidoi.org/jesi/ 2019 Volume 7 Number 1 (September)

http://doi.org/10.9770/jesi.2019.7.1(21)

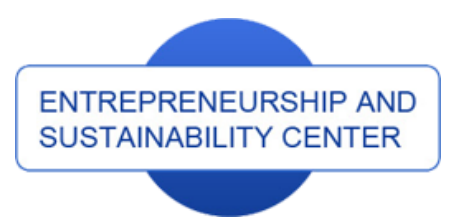

Publisher

http://jssidoi.org/esc/home

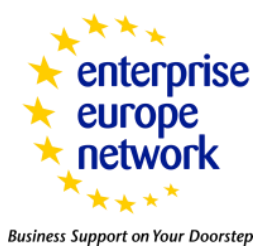

CASPA

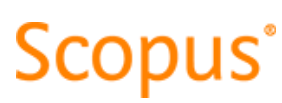

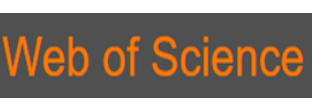

1) Clarivate

Analytics

\title{
SUSTAINABLE PROJECT MANAGEMENT FOR MULTI-AGENT DEVELOPMENT OF ENTERPRISE INFORMATION SYSTEMS*
}

\author{
Aleksandr M. Batkovskiy ${ }^{1}$, Alexey E. Kurennykh ${ }^{2}$, Elena G. Semenova ${ }^{3}$, Vladimir A. Sudakov ${ }^{4}$, \\ Alena V. Fomina ${ }^{5}$, Victor M. Balashov ${ }^{6}$ \\ 1,5 JSC “Central Research Institute of Economy, Management and Information Systems “Electronics”, \\ 12 Kosmonavta Volkova Str., Moscow, 127299, Russian Federation \\ ${ }^{2}$ Moscow Aviation Institute (National Research University), \\ 4 Volokolamsk highway, Moscow, 125993, Russian Federation \\ ${ }^{3}$ Saint-Petersburg State University of Aerospace Instrumentation, \\ 67 Bolshaya Morskaia Str., Saint-Petersburg, 190000, Russian Federation \\ ${ }^{4}$ Keldysh Institute of Applied Mathematics (Russian Academy of Sciences), \\ 4 Miusskaya Sq., Moscow, 125047, Russian Federation \\ ${ }^{6}$ JSC «Scientific and Production Enterpise "Radar MMS”» \\ 37A Novoselkovskaya Str., Saint-Petersburg, 197375, Russian Federation \\ E-mails: ${ }^{1}$ batkovskiya@instel.ru; ${ }^{2}$ alex71321@yandex.ru; ${ }^{3}$ egsemenova@mail.ru; ${ }^{4}$ sudakov@keldysh.ru; \\ 5fomina.a@instel.ru; ${ }^{6}$ balashov-vm@radar-mms.com
}

Received 22 March 2019; accepted 2 July 2019; published 30 September 2019

\begin{abstract}
The paper includes a review of processes in managerial decision-making based on results of multi-agent simulation in development of enterprise information systems. Authors have proposed the multi-agent model, within which agents' actions depend on a hybrid function of preferences. On this basis, authors have formalized the method, with which it is possible to evaluate agents' judgments. The method combines qualitative, quantitative and fuzzy approaches provide by the decision-making theory and the idea of the criteria space divided into sectors. The synthesis of these approaches has made it possible to lower subjective uncertainty inherent in shared managerial decision making. For the multi-agent model, they have drafted event processing algorithms and identified criteria to evaluate simulation results necessary to support decision making in order to identify the most effective option in development of enterprise information system. Authors have also introduced a methodology-related toolkit in the form of software, including the multi-agent model, decision system and optimization module.
\end{abstract}

Keywords: multi-agent simulation; enterprise information systems; hybrid function of preferences; web-based decision support services

\footnotetext{
* The Russian Foundation for Basic Research supported the research under research project No. 18-00-00012 (18-00-00011) COMFI.
} 


\section{ENTREPRENEURSHIP AND SUSTAINABILITY ISSUES}

ISSN 2345-0282 (online) http://jssidoi.org/jesi/ 2019 Volume 7 Number 1 (September) http://doi.org/10.9770/jesi.2019.7.1(21)

Reference to this paper should be made as follows: Batkovskiy, A.M.; Kurennykh, A.E.; Semenova, E.G.; Sudakov, V.A.; Fomina, A.V.; Balashov, V.M. 2019. Sustainable project management for multi-agent development of enterprise information systems, Entrepreneurship and Sustainability Issues 7(1): 278-290. http://doi.org/10.9770/jesi.2019.7.1(21)

JEL Classifications: C10, C44, C52

\section{Introduction}

Information and telecommunication technologies have recently become one of the most crucial factors in enterprise development. Information systems for enterprise resource and product life cycle management are facing their active transformation into a global strategy (Hess, Matt, Benlian, \& Wiesböck, 2016; Kuzmin, 2017), where integrated automation of all the business processes (Shi \& Wang, 2018) is getting more and more in demand.

Application of the potential of information technology in enterprise modernization goes hand in hand with a number of the contradictions that we need to overcome. The main contradiction is that existing function-aimed organizational structures of enterprises do not always suite efficient decision making on introduction of new information technology in the field of design. This is due to a number of closely interrelated factors. This is also an important research objective, solvable, from our point of view, with the shared methodological framework in place that includes decision-making systems based on multi-agent and simulation modelling (Batkovskiy, Konovalova, Semenova, Trofimets, \& Fomina, 2015). For this reason, it is of immediate interest to establish management of designing, development and introduction of the systems that use integration mechanisms. Such management has to ensure building of a shared information space.

Therefore, a research purpose is development of methods that support decision-making, as well as development of the multi-agent model and a number of the statistical criteria for simulation, which contribute into such the distribution of tasks between performers that ensures the highest economic efficiency in building of enterprise information systems.

\section{Literature Review}

Introduction of an information system aims at higher performance of production facilities (Belás, Bartoš, Ključnikov, and Doležal, 2015), as well as supporting of managerial decision-making under conditions of uncertainty and risk (Mohammad, 2015). There are several reasons for this. Note that well-time, accurate and complete managerial data are factors that provide for production efficiency (Batkovskiy, Kalachikhin, Semenova, Telnov, and Fomina, 2016b), while sustainable production scheduling and its monitoring might be achieved with an efficient enterprise information system (Gontarz, Hampl, Weiss, and Wegener, 2015). A current situation brings up to date development of the all-inclusive integrated information systems that provide for necessary managerial functions (Mamary, Shamsuddin, and Aziati, 2014).

For the abovementioned reasons, some methodological aspects in development of information systems and issues of ensured efficient project management in IT system development have not yet been elaborated to a required level and have been intensively discussed (Batkovskiy, Kalachikhin, Semenova, Telnov, and Fomina, 2016a).

Main strategies and approaches to building of large-scale information systems have been developed for a long time (Marcinkowski \& Gawin, 2016) to meet ever-changing market needs. For instance, cloud technologies (Nguyen \& Luc, 2018), sensors and intelligent control systems (Vlasov, Grigoriev, Krivoshein, Shakhnov, Filin, \& Migalin, 2018; Vlasov, Echeistov, Krivoshein, Shakhnov, Filin, \& Migalin, 2018) are of particular importance now. Over the past few decades, many product lifecycle models and group development methodologies have been developed to improve a quality of the software being developed (Mihaela Dima \& Maassen, 2018; Tavares, 


\section{ENTREPRENEURSHIP AND SUSTAINABILITY ISSUES}

ISSN 2345-0282 (online) http://jssidoi.org/jesi/

2019 Volume 7 Number 1 (September)

http://doi.org/10.9770/jesi.2019.7.1(21)

2016). To assess success and quality aspects of the information systems being developed, there are sets of metrics and indicators (Delone \& McLean, 2016).

Many researchers pay attention to development management in case of changed functional requirements to a software product. See the model for evaluation of such cases in Shah, Kama, and Bakar, 2018. See a detailed analysis of problems (incorrect prioritization of tasks, errors in a source code, and incompliance with functional requirements) in Sun, Ni, Lam and $\mathrm{Ng}$ (2016), as well as in Lehtinen, Mäntylä, Vanhanen, Itkonen, and Lassenius, 2014.

Simulation of decision support and analysis of processes has found its applications in many areas of research and in practiced-based solutions (Zulkosky, White, Price, and Pretz, 2016; Marzouk \& Mohamed, 2019; Schubert, Moradi, Asadi, Luotsinen, Sjöberg, Hörling, Linderhed, and Oskarsson, 2015; Güçdemir \& Selim, 2018).

Multi-agent simulation, chosen as one of the main tools in this research, has found its applications in various domains. For instance, for development of network topologies (Kamiyama, 2016), consciousness (Arsene \& Dumitrache, 2017) and transportation-related tasks (Mastio, Zargayouna, Scemama, and Rana, 2018). The second most important tool applied in this research is the decision support system. For instance, in management of corporations (Chen, Yen, Lin, and Chou, 2018), when people decide on location of production facilities (Kuzmin, 2018) or a reasonable configuration of the product being designed (Buchert, Ko, Graf, Vollmer, Alkhayat, Brandenburg, Stark, Klocke, Leistner, and Schleifenbaum, 2019). Object ranking methods have been also in wide use and have faced their development (Asadabadi, 2018; Safarzadeh, Khansefid, and Rasti-Barzoki, 2018). We are aware of the attempts to describe a development process of enterprise information systems with the help of the multi-agent model. However, specifics of its application does not make it possible to have full and comprehensive review of the problem of large-scale project management, where projects assume development of information systems.

\section{Materials and methods}

\subsection{Simulation formalization of EIS development}

In this research, the methodological framework for applications of decision-making support models have found their further development with regard to tasks of planning and management in the development and introduction of enterprise information systems.

There are the following components in the development process model (DM):

a) Tasks for development of the modules that an enterprise information system includes, for which there is a need in a research at a pre-design stage.

b) Alternatives are options of EIS development. They all find their representation in the form of a relevant model with a specific set of parameters (for instance, distribution of powers at stages of design and development) and, possibly, unique structure. The models are ranked to help decision makers to choose a rational scenario for EIS development.

c) Parameters of the simulation model and criteria for evaluation of simulation results are main criteria for ranking of alternatives.

To state the problem in a formal way, let us introduce the following denotations.

$$
T=\left\{T_{1}, T_{2}, \ldots, T_{i}, \ldots, T_{n}\right\}, i=\overline{1, n},
$$

where $T$ is an array of assignments (orders for EIS development). 
For each assignment, there is a finite sub-array of alternatives shown with models $A_{i}$ :

$$
A_{i}=\left\{\alpha_{i 1}, \alpha_{i 2}, \ldots, \alpha_{i j}, \ldots, \alpha_{i m}\right\}, i=\overline{1, n} ; j=\overline{1, m},
$$

where $\alpha_{i, j}$ is the $j$-th alternative for the $i$-the assignment;

$$
M=\left\{M_{1}, M_{2}, \ldots, M_{i}, \ldots, M_{n}\right\}, i=\overline{1, n}
$$

$M$ is an array of options of the models compared with each sub-array of alternatives in such a way as each set of alternatives $A_{i}$ has array of models $M_{i}$, where:

$$
M_{i}=\left\{\mu_{1}\left(\Lambda_{1}, \Xi_{1}\right), \mu_{2}\left(\Lambda_{2}, \Xi_{2}\right), \ldots, \mu_{j}\left(\Lambda_{j}, \Xi_{j}\right), \ldots, \mu_{m}\left(\Lambda_{m}, \Xi_{m}\right)\right\}, i=\overline{1, n} ; j=\overline{1, m}
$$

where $\mu_{j}$ is a specific implementation of a model, while

$$
\begin{aligned}
& \Lambda_{j}=\left\{\lambda_{1}, \lambda_{2}, \ldots, \lambda_{l}, \ldots, \lambda_{k_{j}}\right\}, l=\overline{1, k_{j}} ; j=\overline{1, m}, \\
& \Xi_{j}=\left\{\xi_{1}, \xi_{2}, \ldots, \xi_{s}, \ldots, \xi_{v_{j}}\right\}, l=\overline{1, v_{j}} ; j=\overline{1, m}
\end{aligned}
$$

where $\Lambda_{j}$ is an array of input data - model parameters, while $\Xi_{j}$ is a vector of criteria for the evaluation of simulation results.

The above-mentioned assumes that there is a need in introduction of the algorithm that establishes correlation between objects $T, A, M, L, \Xi$ :

$$
\forall T_{i} \exists A_{i}: \forall \alpha_{i, j}\left(\alpha_{i, j} \in A_{i}\right) \exists \mu_{j}\left(\Lambda_{j}, \Xi_{j}\right)\left[\mu_{j} \in M_{i}\right], i=\overline{1, n} ; j=\overline{1, m}
$$

There is a separated review of model optimization (rationalization). This process refers to a selection of the most favourable vector for model parameters. In this case, there is an aim to achieve the indicators that a user wants for EIS development process. Let us introduce the following denotations:

$n$ is dimensionality of the model parameters' vector;

$m$ is dimensionality of the vector of evaluation criteria for simulation results;

$X=\left\{x_{1}, x_{2}, \ldots x_{i}, \ldots x_{n}\right\}, i=\overline{1, n}$ is a set of parameters for a model;

$Y=\left\{y_{1}, y_{2}, \ldots y_{j}, \ldots y_{m}\right\}, j=\overline{1, m}$ is a vector of evaluation criteria for simulation results;

$A=\left\{a_{1}, a_{2}, \ldots a_{i}, \ldots a_{n}\right\}, i=\overline{1, n}$, where $a_{i}$ is a down-top constraint by amount of available resources in EIS development;

$B=\left\{b_{1}, b_{2}, \ldots b_{i}, \ldots b_{n}\right\}, i=\overline{1, n}$, where $b_{i}$ is a top-down constraint by amount of available resources in EIS development.

With the denotations introduced, the formal record of the task has one of the following forms depending on user's preferences:

$$
\begin{aligned}
& \max _{X}\left\{y_{j}=f(X)\right\} \\
& \min _{X}\left\{y_{j}=f(X)\right\}
\end{aligned}
$$

In Equation (7), $f(X)$ refers to a transformation of the vector of parameters into one of criteria $y_{j}$ to evaluate simulation results and chosen by a user as a target function. Given the resource constraints:

$$
\begin{aligned}
& x_{i} \leq b_{i},(i=\overline{1, n}) \\
& x_{i} \geq a_{i},(i=\overline{1, n})
\end{aligned}
$$


Note that almost in each tasks related to CIS development, $m>1$. That is, the optimization problem belongs to the class of multi-criteria problems. To work with this class of engineering challenges, we applied the hybrid method for preference identification. With this scenario, it is possible to use quantitative ranking methods for the alternatives that fall in the same area (Spina, 2016).

When people build, upgrade and introduce IESs, it is necessary to provide a project manager with probabilistic and temporal performance metrics for the personnel involved in parametric and structural changes in software development. This is necessary for taking necessary measures and making influence performers (Sudhaman \& Thangavel, 2015).

To debug and explore a chance of an application of the considered approach, authors built the development model (DM) for an enterprise information system. Taking into account the accepted assumptions, there are the following stages in a flow of applications in development of the enterprise information system (Fig. 1).

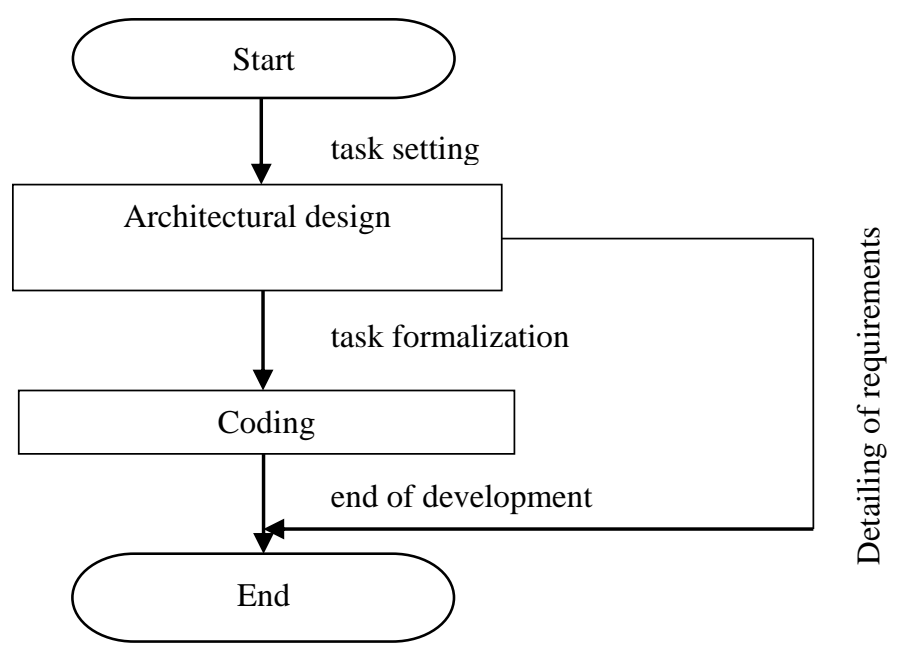

Fig. 1. Diagram of interconnected stages in the software development simplified cycle

DM is based on simplified development of software. There are the following events in the model considered in enterprise information system development: (1) application enters the system, (2) application processing at the Architecture stage, (3) application processing at the Development stage. See the relationship of the abovementioned model events in Fig. 2.

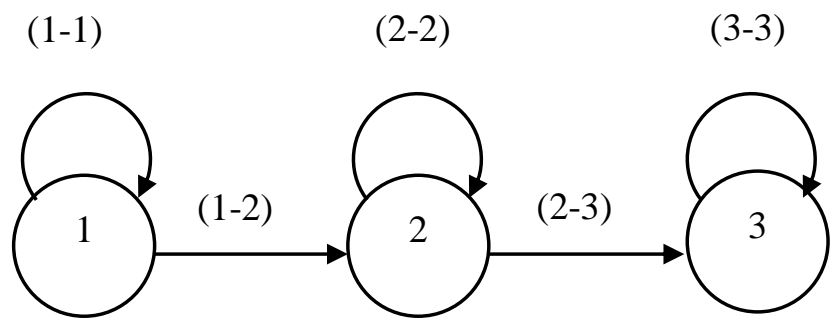

Fig. 2. Model event graph

Each transition on the model event graph triggers scheduling of a model event. It is enough to have such a relatively simple model for development for a further test and debugging of an approach, as well as substantiating of its possible use in more complex tasks of IES development with the multi-agent models applied. 


\subsection{Multi-agent model for development of enterprise information system}

To achieve high performance of employees when they build, update, apply and maintain the information system (Wanderley, Menezes, Gusmão, \& Lima, 2015), (Choudhary, Kumar, Kumar, Mishra, \& Catal, 2018), based on the abovementioned approach, the authors developed the multi-agent model of the development process (DM).

It is assumed that in the model under consideration, agents have preference functions and they are guided by such functions. It is assumed that the agent's preference function (that belongs to class Problem Owner [PO]) is without changes. For the tasks that allow the optimization of a structure, it is possible to set functions of the agents that belong to class Object $(\mathrm{O})$, for the other tasks, $O$ function stays unchanged. The preference function for an agent that belongs to class Subject $(C)$ has two parts: it includes one's own interests that are assumed unchanged, and the interests affected by $P O$. In its last part, the preference function is adjustable. Virtual agents $(V A s)$ are, as a rule, made with such the system of preferences as to provide a search for a global optimum. Agent's preferences are often imprecise and unclear. Besides, estimated judgments of agents by criteria can often be obtained with a certain error, which is reasonable to be taken into account. To use fuzzy judgments in the model, it is necessary to apply the apparatus from the theory of fuzzy sets. See the diagram that describes a subject area and task transitions between agents in Fig. 3

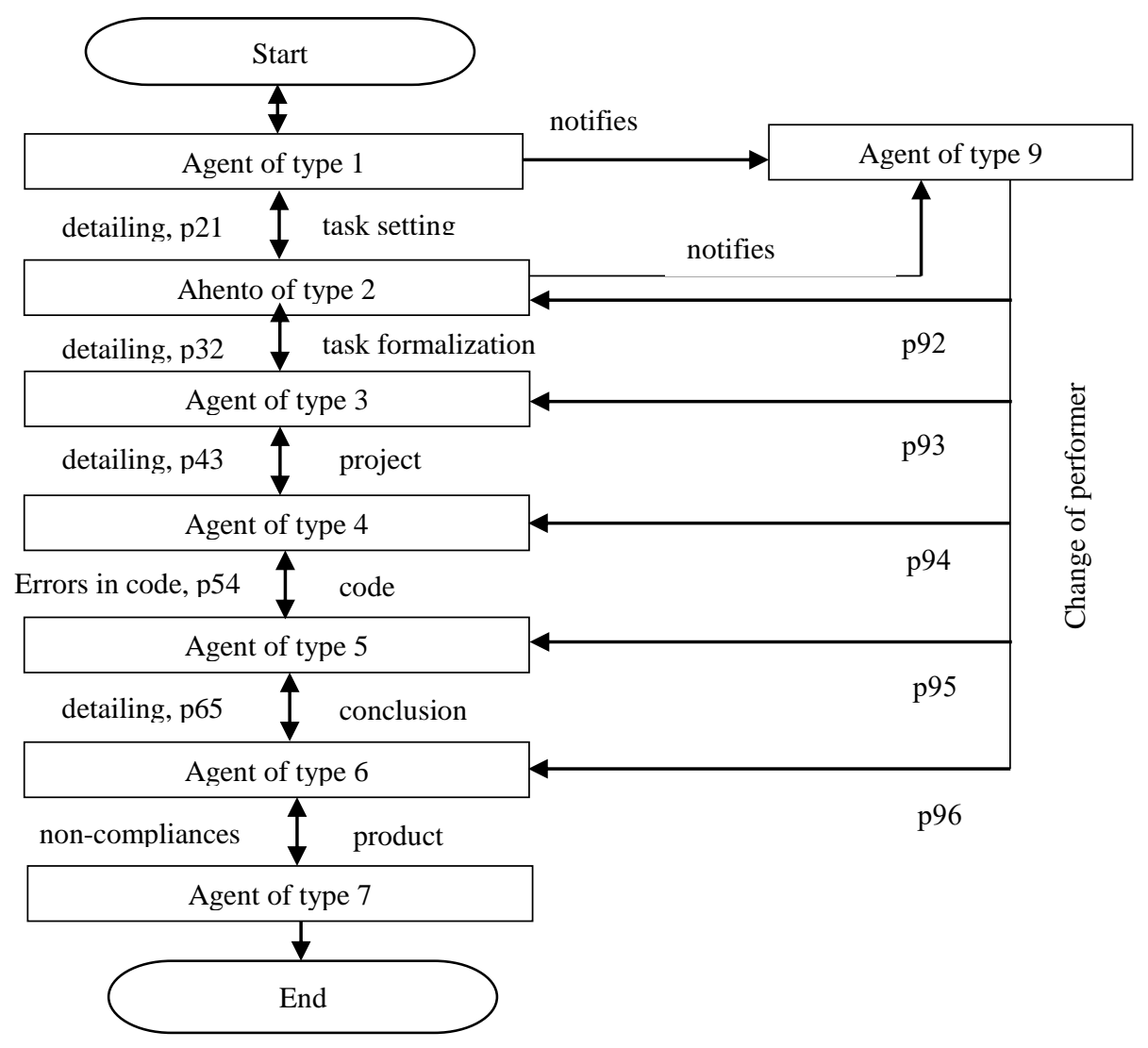

Fig. 3. Application flow chart in the multi-agent model for development of enterprise information system 
Tasks to change the EIS arise in communication between agents of type 1 and type 2. After this, a task is successively transferred by agents of type 2 to agents of type 3 and so forth. With certain non-zero probability (p21, p32, p43, p54, p65, p76), it can return to agents at any of the previous stages. The information model of inter-agent interaction looks like a backboard.

Agents independently choose tasks, based on their own preference function, while others are forcedly assigned to performers by the agent of type 9 based on his/her preference function. Furthermore, the agent of type 9 may block a possibility of independent allocation of tasks between some other agents of types 2-6. Any of the abovementioned operations might happen with certain probabilities (p92, p93, p94, p95, p96).

It is possible to present a choice of the most suitable ('profit-bearing') employee as a process (to solve a task) in the following formal way:

$$
I=\min _{i} \arg \left\{\max _{i}\left(S_{i j n} K S_{k n}+\left(1-L_{i n}(t)\right) K L_{k n}\right)\right\}
$$

where $i$ is a unique identifier of a software developer; $j$ is a unique identifier of a type of an application; $k$ is a unique priority identifier; $n$ is a number of a service stage; $S_{i, j, n}$ is experience of a developer with identifier $i$ to perform tasks with identifier $j$ at stage number $n ; L_{i, n}(t)$ is a load of a developer with identifier $i$ at moment of time $t$ at stage number $n ; K S_{k, n}$ is a weight contributed by experience of an employee for a case of an application with $k$ priority at stage number $n ; K L_{k, n}$ is a weight contributed be the load of the employee for the case of an application with $k$ priority at stage number $n$.

\section{Results}

\subsection{Software for application of the multi-agent model}

The most important result from the research is the developed multi-agent model, in which people apply the considered simulation algorithms. See the diagram of classes within the developed model in Fig. 4. 


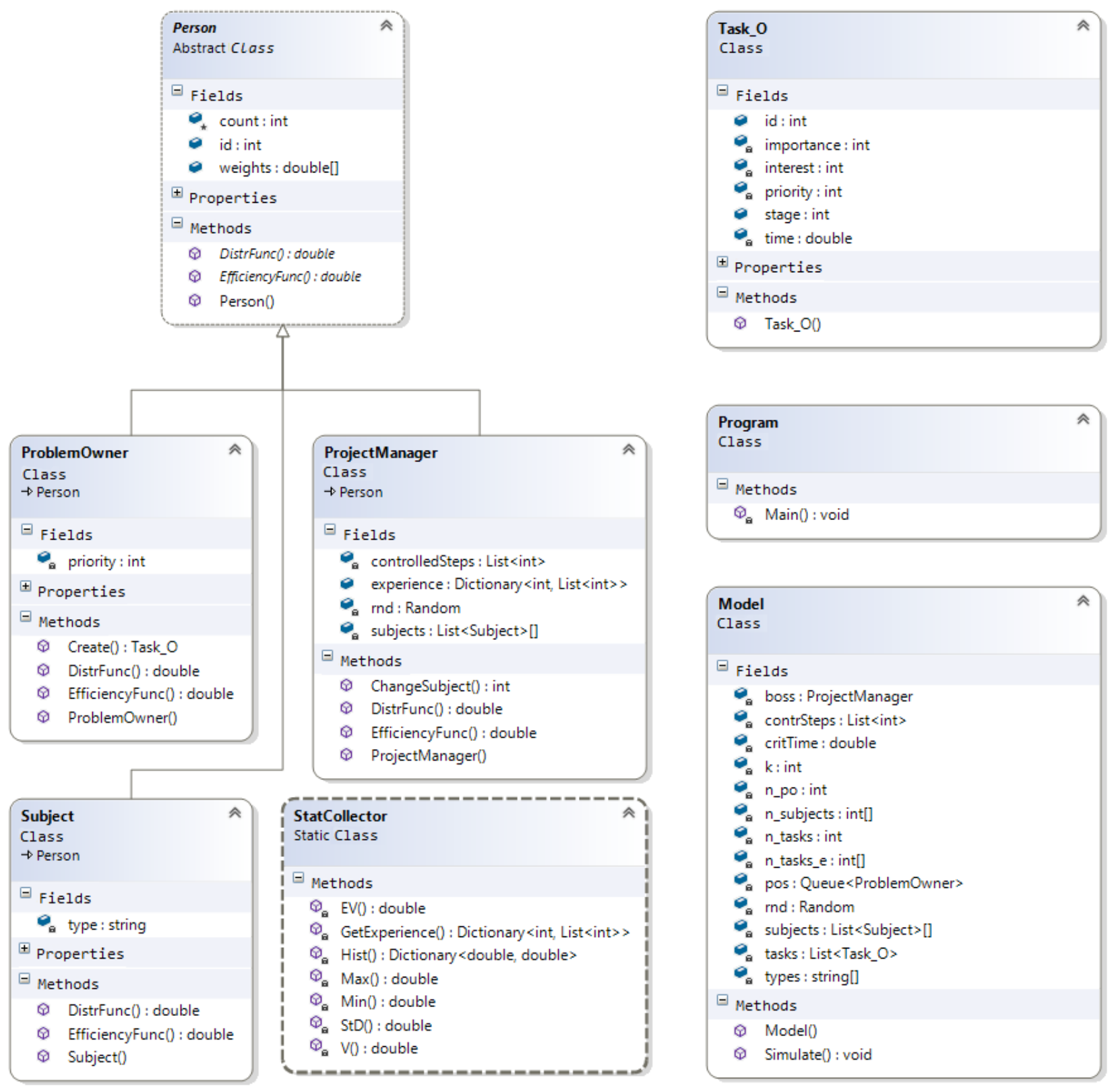

Fig. 4. Diagram of classes in the multi-agent model for enterprise information system development

The ProblemOwner class performs functions of the $V P$-type agent. It is possible here to set tasks using the Create method, perform the distribution function with regard to a number of tasks and preference function, DistrFunc and EfficiencyFunc, respectively. The ProjectManager class makes it possible to implement functions of the 9type agent. It has its own preference function regarding a choice of a performer for a task (Equation 9) EfficiencyFunc, and the method that makes it possible to change performers of tasks - ChangeSubject. The Subject class describes all the other $C$-type agents considered within the model. The Task_ $O$ class describes the $\underline{\mathrm{O}}$ object, i.e. the task that is to be solved. The StatCollector class is auxiliary used to gather statistics when the model is in operation. The Model class provides a description of model parameters, as well as methods, with 
which we apply the simulation algorithm. The described multi-agent model was made using C\# in MS Visual Studio.

\subsection{Software to apply the hybrid method of preference identification}

There is the open access module at ws-dss.com for cloud computing. It contains the developed function that makes it possible to apply the hybrid method of preference identification (Fig. 5).

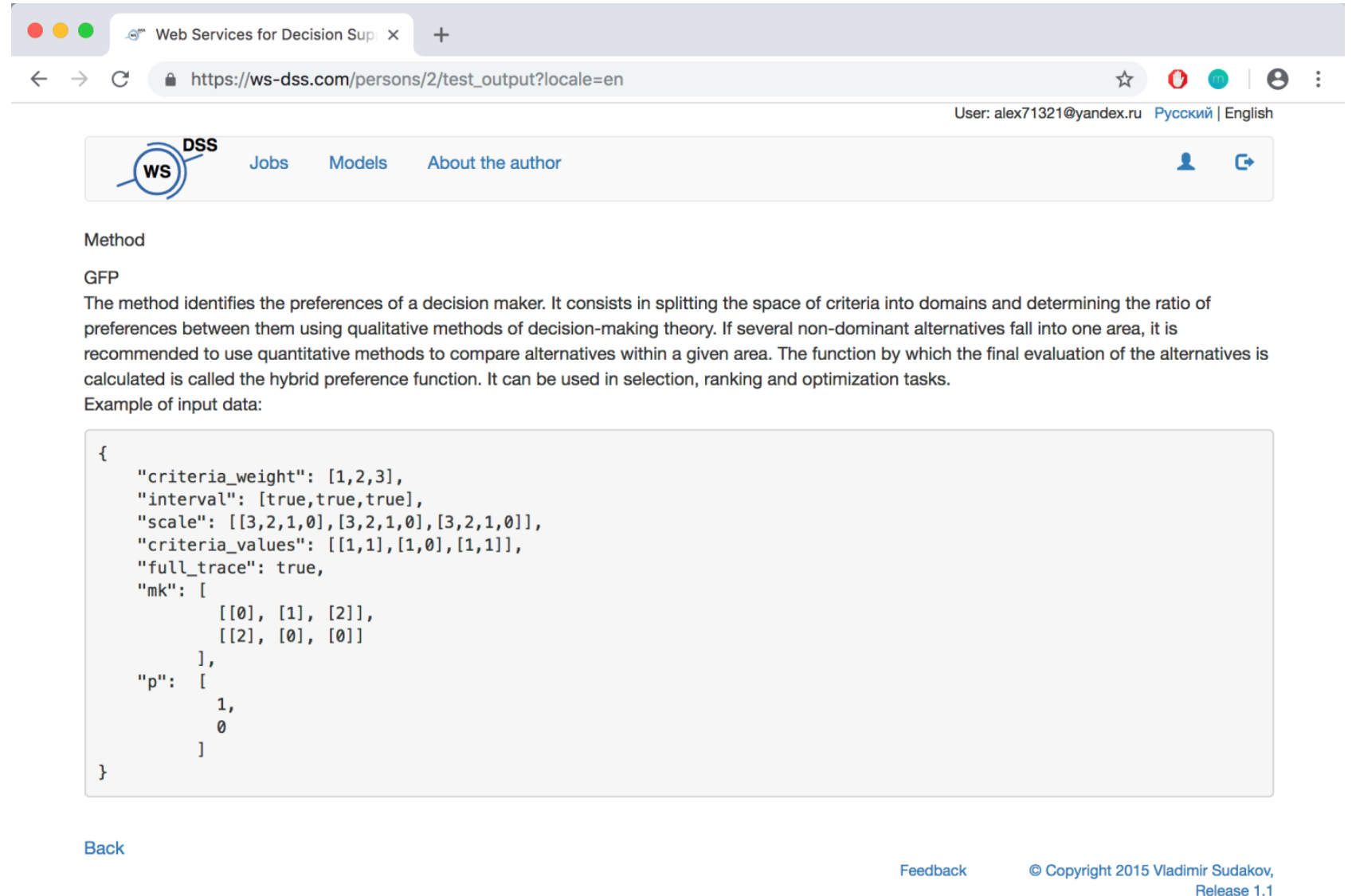

Fig. 5. Hybrid preference function call interface

The authors has developed the system using open source software, which is a positive aspect (Paschali, Ampatzoglou, Bibi, Chatzigeorgiou, \& Stamelos, 2017; Olson, Johansson, \& De Carvalho, 2018). Modules of WS-DSS decision support system, as well as in the domain model, are independent agents. Thus, there is no single framework in the system. Agents interact using an exchange of messages. The described and introduced approach using agents independent of each other results in almost no communication between modules. This significantly reduces labour costs for changes in the system and significantly improves its performance (Yatsalo, Didenko, Gritsyuk, \& Sullivan, 2015; Rodríguez-Padial, Marín, \& Domingo, 2015).

In its development, authors considered that the enterprise information system is to cover all the aspects in the enterprise's life (procurement, production, sales, personnel management, etc.). In the overwhelming majority of cases, each relevant aspect has an assigned employee in charge, who assigns tasks based on his/her distribution function and preference. Besides, the model takes into account the factor of interaction in a team shown by chains of transfers and returns of tasks between performers, as well as the ability of agents to choose tasks by their own 


\section{ENTREPRENEURSHIP AND SUSTAINABILITY ISSUES}

ISSN 2345-0282 (online) http://jssidoi.org/jesi/ 2019 Volume 7 Number 1 (September) http://doi.org/10.9770/jesi.2019.7.1(21)

preference functions. All the above mentioned suggest that the proposed multi-agent model adequately and fully describes actual development and introduction of enterprise information systems.

\section{Conclusion}

In the research, authors developed the algorithmic decision-making support based on multi-agent simulation. They also piloted the heuristic method intended for rationalization of the parameters that the model has. An advantage of the developed multi-agent model compared to the models referred to by similar research, lies in high level of details in the process of information system building (task setting, requirement review, development, introduction, etc.) with due regard to personal preferences. Authors offered the hybrid method, with which it is possible to identify preferences for a multi-criteria analysis of options for the multi-agent model of the development process. It covers the expert's overall system of values in terms of high-dimensional criteria, including both qualitative, and quantitative components. Developed software includes independent services that interact with each other using network data transfer protocols, which makes it easy to adjust and enhance the model to meet changing needs. Integration of methods for decision support and multi-agent simulation within a shared system framework provides the synergistic effect in management of building and introduction of enterprise information systems.

\section{References}

Arsene, O. and Dumitrache, I. (2017). Mind as multi-resolution system based on multi-agent architecture. Biologically Inspired Cognitive Architectures, 20, 31-38. https://doi.org/10.1016/j.bica.2017.02.003

Asadabadi, M.R. (2018). The stratified multi-criteria decision-making method. Knowledge-Based Systems, 162, 115-23. https://doi.org/10.1016/j.knosys.2018.07.002

Batkovskiy, A.M., Kalachikhin, P.A., Semenova, E.G., Telnov, Yu.F., and Fomina, A.V. (2016a). Component methodology for creating and implementing organizational innovations in business companies. Indian Journal of Science and Technology, 9(27), 121-34. http://doi.org/10.17485/ijst/2016/v9i27/97658

Batkovskiy, A.M., Kalachikhin, P.A., Semenova, E.G., Telnov, Yu.F., and Fomina, A.V. (2016b). Economic-mathematical model and mathematical methods for substantiating the choice of the company innovation strategy. Indian Journal of Science and Technology, 9(27), 99-111. http://doi.org/10.17485/ijst/2016/v9i27/97662

Batkovskiy, A.M., Konovalova, A.V., Semenova, E.G., Trofimets, V.Ya., AND Fomina, A.V. (2015). Study of economic systems using the simulation-based statistical modelling method. Mediterranean Journal of Social Sciences, 6(4), 369-80. http://doi.org/10.5901/mjss.2015.v6n4s4p369

Belás, J., Bartoš, P., Ključnikov, A., and Doležal, J. (2015). Risk perception differences between micro-, small and medium enterprises. Journal of International Studies, 8, 20-30.

Buchert, T., Ko, N., Graf, R., Vollmer, T., Alkhayat, M., Brandenburg, E., Stark, R., Klocke, F., Leistner, P., and Schleifenbaum, J.H. (2019). Increasing resource efficiency with an engineering decision support system for comparison of product design variants. Journal of Cleaner Production, 210, 1051-62. https://doi.org/10.1016/j.jclepro.2018.11.104

Chen, P.S., Yen, D.C., Lin, S.C., and Chou, C.S. (2018). Toward an IT investment decision support model for global enterprises. Computer Standards \& Interfaces, 59, 130-40. https://doi.org/10.1016/j.csi.2018.04.001

Choudhary, G.R., Kumar, S., Kumar, K., Mishra, A., and Catal, C. (2018). Empirical analysis of change metrics for software fault prediction. Computers \& Electrical Engineering, 67, 15-24. http://doi.org/10.1016/j.compeleceng.2018.02.043 


\section{ENTREPRENEURSHIP AND SUSTAINABILITY ISSUES}

ISSN 2345-0282 (online) http://jssidoi.org/jesi/ 2019 Volume 7 Number 1 (September) http://doi.org/10.9770/jesi.2019.7.1(21)

Delone, W., McLean, E. (2016). Information systems success measurement. Foundations and Trends in Information Systems, 2, 1-116. http://doi.org/10.1561/2900000005

Gontarz, A.M., Hampl, D., Weiss, L., and Wegener, K. (2015). Resource consumption monitoring in manufacturing environments. Procedia CIRP, 26, 264-69. http://doi.org/10.1016/j.procir.2014.07.098

Güçdemir, H., Selim, H. (2018). Integrating simulation modelling and multi criteria decision making for customer focused scheduling in job shops. Simulation Modelling Practice and Theory, 88, 17-31. http://doi.org/10.1016/j.simpat.2018.08.001

Hess, T., Matt, C., Benlian, A., and Wiesböck, F. (2016). Options for formulating a digital transformation strategy. MIS Quarterly Executive, 15, 123-39.

Kamiyama, N. (2016). Generating desirable network topologies using multi-agent system. Computer Communications,76, 87-100. https://doi.org/10.1016/j.comcom.2012.07.019

Kuzmin, E.A. (2017), Risk and uncertainty in concept of corporate lifecycle. Problems and Perspectives in Management, 15(1), 107-114. https://doi.org/10.21511/ppm.15(1).2017.11

Kuzmin, E.A., and Dubrovsky, V. Zh. (2018). Estimation method of favor level of external business conditions during projects implementation. In Proceedings of International Conference on Research Paradigms Transformation in Social Sciences RPTSS (pp. 262-82). https://dx.doi.org/10.15405/epsbs.2018.12.83

Lehtinen, T.O.A., Mäntylä, M.V., Vanhanen, J., Itkonen, J., and Lassenius, C. (2014). Perceived causes of software project failures - an analysis of their relationships. Information and Software Technology, 56(6), 2014, 623-43. https://doi.org/10.1016/j.infsof.2014.01.015

Mamary, Y.H.S., Shamsuddin, A., and Aziati, A. (2014). The Role of different types of information systems in business organizations: a review. International Journal of Research, 1, 1279-86.

Marcinkowski, B., Gawin, B. (2016). Project management in international IT ventures - does the practice go hand in hand with theory? Conference Proceedings Information Systems: Development, Research, Applications, Education, 264, 144-152. http://doi.org/10.1007/978-3-319-46642-2_10

Marzouk, M., Mohamed, B. (2019). Integrated agent-based simulation and multi-criteria decision making approach for buildings evacuation evaluation. Safety Science, 112, 57-65. http://doi.org/10.1016/j.ssci.2018.10.010

Mastio, M., Zargayouna, M., Scemama, G., and Rana, O. (2018). Two distribution methods for multiagent traffic simulations. Simulation Modelling Practice and Theory, 89, 35-47. https://doi.org/10.1016/j.simpat.2018.09.005

Mihaela Dima, A., Maassen, M.A. (2018). From waterfall to agile software: development models in the IT sector, 2006 to 2018. Impacts on company management. Journal of International Studies, 11, 315-326. https://doi.org/10.14254/2071$\underline{8330.2018 / 11-2 / 21}$

Mohammad D. (2015). Exploring the use of an Information visualization tool for decision support under uncertainty and risk. In Proceedings of the International Conference on Engineering MIS 2015 (ICEMIS '15). New York, NY, USA: ACM. http://doi.org/10.1145/2832987.2833050

Nguyen, T.D., V.T. Luc, K. (2018). Information systems success: empirical evidence on cloud-based ERP. Lecture Notes in Computer Science, 11251, 471-485. http://doi.org/10.1007/978-3-030-03192-3_3

Olson, D.L., Johansson, B., and De Carvalho, R.A. (2018). Open source ERP business model framework. Robotics and Computer-Integrated Manufacturing, 50, 30-36. http://doi.org/10.1016/j.rcim.2015.09.007 


\section{ENTREPRENEURSHIP AND SUSTAINABILITY ISSUES}

ISSN 2345-0282 (online) http://jssidoi.org/jesi/ 2019 Volume 7 Number 1 (September) http://doi.org/10.9770/jesi.2019.7.1(21)

Paschali, M.E., Ampatzoglou, A., Bibi, S., Chatzigeorgiou, A., and Stamelos, I. (2017). Reusability of open source software across domains: a case study. Journal of Systems and Software, 134. 211-227. http://doi.org/10.1016/j.jss.2017.09.009

Rodríguez-Padial, N., Marín, M., and Domingo, R. (2015). Strategic framework to maintenance decision support systems. Procedia Engineering, 132, 903-910. https://doi.org/10.1016/j.proeng.2015.12.576

Safarzadeh, S., Khansefid, S., and Rasti-Barzoki, M. (2018). A group multi-criteria decision-making based on best-worst method. Computers \& Industrial Engineering, 126, 111-121. https://doi.org/10.1016/j.cie.2018.09.011

Schubert, J., Moradi, F., Asadi, H., Luotsinen, L., Sjöberg, E., Hörling, P., Linderhed, A., and Oskarsson, D. (2015). Simulation-based decision support for evaluating operational plans. Operations Research Perspectives, 2, 36-56. http://doi.org/10.1016/j.orp.2015.02.002

Shah, J., Kama, N., Bakar N.A. (2018). A novel effort estimation model for software requirement changes during software development phase. International Journal of Software Engineering \& Applications (IJSEA), 9(6), 11-30. https://doi.org/10.5121/ijsea.2018.9602

Shi, Z., Wang, G. (2018). Integration of big-data ERP and business analytics (BA). Journal of High Technology Management Research, 29(2), 141-150. http://doi.org/10.1016/j.hitech.2018.09.004

Spina, L.D. (2016). Evaluation decision support models: highest and best use choice. Procedia - Social and Behavioral Sciences, 223, 936-43. http://doi.org/10.1016/j.sbspro.2016.05.323

Sudhaman, P., Thangavel, C. (2015). Efficiency analysis of ERP projects-software quality perspective. International Journal of Project Management, 33(4), 961-70. https://doi.org/10.1016/j.ijproman.2014.10.011

Sun, H., Ni, W., Lam, R., and Ng, C.Y. (2016). A Stage-by-stage assessment of enterprise resource planning implementation: An empirical study from Hong Kong. Journal of Global Information Technology Management, 19(2), 104-27. http://doi.org/10.1080/1097198X.2016.1173387

Tavares, B. (2016). Risk management analysis in software projects which use the scrum framework. Intl. Trans. in Op. Res. 00, 1-22. http://doi.org/10.1111/itor.12401

Vlasov, A. I., Grigoriev, P.V, Krivoshein, A. I., Shakhnov, V. A., Filin, S. S., \& Migalin, V. S. (2018). Smart management of technologies: Predictive maintenance of industrial equipment using wireless sensor networks. Entrepreneurship and Sustainability Issues, 6(2), 489-502. http://doi.org/10.9770/jesi.2018.6.2(2)

Vlasov, A.I., Echeistov, V.V, Krivoshein, A.I., Shakhnov, V.A., Filin, S.S., \& Migalin, V.S. (2018). An information system of predictive maintenance analytical support of industrial equipment. Journal of Applied Engineering Science, 16(4), 515-22. http://doi.org/10.5937/jaes16-18405

Wanderley, M., Menezes, J., Gusmão, C., and Lima, F. (2015). Proposal of risk management metrics for multiple project software development. Procedia Computer Science, 64, 1001-9. http://doi.org/10.1016/j.procs.2015.08.619

Yatsalo, B., Didenko, V., Gritsyuk, S., and Sullivan, T. (2015) A framework for multi-criteria decision analysis. International Journal of Computational Intelligence Systems, 8(3), 467-89. http://doi.org/10.1080/18756891.2015.1023586

Zulkosky, K.D., White, K.A., Price, A.L., and Pretz, J.E. (2016). Effect of simulation role on clinical decision-making accuracy. Clinical Simulation in Nursing, 12(3), 98-106. http://doi.org/10.1016/j.ecns.2016.01.007 


\title{
ENTREPRENEURSHIP AND SUSTAINABILITY ISSUES
}

ISSN 2345-0282 (online) http://jssidoi.org/jesi/

2019 Volume 7 Number 1 (September)

http://doi.org/10.9770/jesi.2019.7.1(21)

\section{Aknowledgements}

The Russian Foundation for Basic Research supported the research under research project No. 18-00-00012 (18-00-00011) COMFI.

Aleksandr M. BATKOVSKIY, Dr. Sci. (Economics), Senior Researcher, JSC “Central Research Institute of Economy, Management and Information Systems "Electronics", Moscow, Russian Federation. Research interests: economics of industry, management, production efficiency, sustainable systems.

ORCID ID: orcid.org/0000-0002-5145-5748

\begin{abstract}
Alexey E. KURENNYKH, Engineer, Moscow Aviation Institute (National Research University), Moscow, Russian Federation. Research interests: management decision support systems, Industry 4.0, mathematical programming, information systems, simulation modeling, multi-criteria analysis of alternatives, optimization algorithms.

ORCID ID: orcid.org/0000-0001-5200-1775
\end{abstract}

Elena G. SEMENOVA, Dr. Sci. (Engineering), Professor, Director of the Institute of Innovation and master basic training, SaintPetersburg State University of Aerospace Instrumentation, St. Petersburg, Russian Federation. Research interests: innovative activity, modeling, sustainable systems, management, applied mathematics.

ORCID ID: orcid.org/0000-0001-8312-4903

Vladimir A. SUDAKOV, Dr. Sci. (Engineering), Leading researcher, Keldysh Institute of Applied Mathematics (Russian Academy of Sciences), Moscow, Russian Federation. Research interests: mathematical modeling, innovative companies, corporate information systems, optimization strategies, fuzzy logic, infrastructure projects, multi-criteria tasks, automation of production processes.

ORCID ID: orcid.org/0000-0002-1658-1941

Alena V. FOMINA, Dr. Sci. (Economics), Assistant professor, JSC “Central Research Institute of Economy Management and Information Systems "Electronics", Moscow, Russian Federation. Research interests: regional economy, industrial economy, development strategies and restructuring, strategic planning, high-tech production structures, financial and economic planning, sustainable economic systems.

ORCID ID: orcid.org/0000-0002-5853-0309

Victor M. BALASHOV, Dr. Sci. (Engineering), Professor, JSC «Scientific and Production Enterpise "Radar MMS"», Saint-Petersburg, Russian Federation. Research interests: reengineering, enterprise economics, economic and mathematical modeling.

ORCID ID: orcid.org/0000-0003-4642-5701

Register for an ORCID ID:

https://orcid.org/register

Copyright (C) 2019 by author(s) and VsI Entrepreneurship and Sustainability Center

This work is licensed under the Creative Commons Attribution International License (CC BY).

http://creativecommons.org/licenses/by/4.0/

CC) (i) Open Access 